\title{
Korrigendum
}

Andreas Lorenz

\section{Korrigendum zu: Andreas Lorenz. Auf neuen Pfaden mit alten Spielen: Retrogaming- Technologie für Bibliotheken}

https://doi.org/10.1515/bd-2020-0073

Korrigendum zu: Auf neuen Pfaden mit alten Spielen: Retrogaming-Technologie für Bibliotheken. Bibliotheksdienst. Band 54, Heft 5, Seiten 313-344. (DOI:10.1515/ bd-2020-0044):

Anmerkung der Redaktion: Bei oben genanntem Artikel ist uns leider auf Seite 340 ein Fehler unterlaufen. Der erste Satz auf der Seite hatte am Satzende ursprünglich zwei Fußnoten, nämlich die Fußnoten 42 und 43. Die zweite Fußnote 43 ist leider nicht übernommen worden. Die verbliebene Fußnote 42 entspricht korrekterweise der Fußnote 43 auf der Seite unten im Fußnotenbereich und die „verloren gegangene“ Fußnote 43 entspricht der Fußnote 42 im Fußnotenbereich. Die Fußnote $44 \mathrm{im}$ Text verweist dann im Fußnotenbereich auf die Fußnote 45, 45 im Text auf 46 im Fußnotenbereich und so fort. Somit verschiebt sich die Zuordnung von Fußnote im Text zu Fußnote im Fußnotenbereich bis zum Textende um je eine Fußnote. Wir bitten dies zu entschuldigen!

Außerdem wurde auf Seite 343 die Fußnote 55 (die korrekterweise auf Fußnote 56 im unteren Bereich verweisen muss) zur Fußnote 5556. Auch dies bitten wir zu entschuldigen! 